International Journal of Physical Sciences and Engineering
Available online at http://sciencescholar.us/journal/index.php/ijpse
Vol. 2 No. 2, August 2018, pages: 101 110
e-ISSN : 2550-6943, p-ISSN : 2550-6951
https://doi.org/10.29332/ijpse.v2n2.172

\title{
Development and Optimization of the Ratio Vegetation Index on the Visible and Infrared Spectrum
}

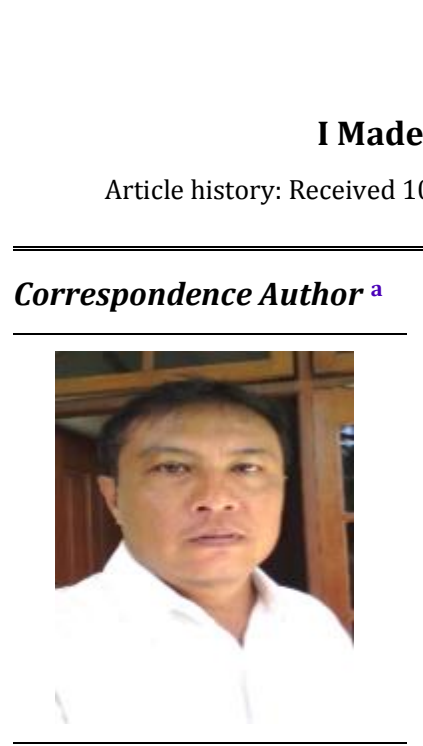

Keywords

Clove vegetation

distribution;

Development;

Infrared spectrum;

RVI optimization;

Visible;
Made Yuliara a, Gusti Ngurah Sutapa ${ }^{\text {b }}$, Gde Antha Kasmawan c Available online 20 August 2018

\begin{abstract}
This study aims to find a suitable vegetation index model to analyze the distribution of clove vegetation in Buleleng regency, Bali. Vegetation index model Ratio Vegetation Index (RVI) extracted from Landsat 8 was developed in the visible spectrum $(\lambda=0.450-0.680 \mu \mathrm{m})$ and infrared $(\lambda=0.845-2.300 \mu \mathrm{m})$. Development methods are carried out on the basis of the spectral reflectance response characteristics of the dominant electromagnetic waves from the visible and infrared spectra of vegetation. Created a multiple regression relationship results from scattergram that links RVI vegetation index with band $3=\mathrm{B} 3$, band $5=\mathrm{B} 5$, band $6=\mathrm{B} 6$, and band $7=\mathrm{B} 7$. Optimization strategy is carried out by dividing the development of RVI with a variable number factor. There are 4 forms of RVI vegetation index models from the development and optimization of the visible and infrared spectra. Of the 4 new vegetation index forms, which provide optimal results and close to extensive data from the Forestry and Plantation Service, Buleleng regency, Bali is $\mathrm{RVI}_{\text {new }}=0.0022+$ $0.00142 * \mathrm{~B} 3+0.00028 * \mathrm{~B} 5+0.00054 * \mathrm{~B} 6+0.00096 * \mathrm{~B} 7$. The area produced by this vegetation index model in analyzing the distribution of clove vegetation is 7667.82 ha. This area is $99.40 \%$ of the average data area of the Forestry and Plantation Service, Buleleng regency, Bali in 2014, which is 7622.32 ha. The dominant distribution of clove vegetation is in the rare category with an area of 7441.74 ha.
\end{abstract}

e-ISSN: 2550-6943, p-ISSN: 2550-6951 ๑Copyright 2018. The Author. SS Journals Published by Universidad Técnica de Manabí. This is an open-access article under the CC BY-SA 4.0 license (https://creativecommons.org/licenses/by-sa/4.0/) All rights reserved.

a Physics Departement, Faculty of Mathematics and Science, Udayana University, Denpasar, Bali, Indonesia

b Physics Departement, Faculty of Mathematics and Science, Udayana University, Denpasar, Bali, Indonesia

c Agricultural Science Doctorate, Udayana University, Denpasar, Bali, Indonesia 


Contents
Abstract
1. Introduction
2. Research Method
3. Results and Analysis
3.1 Result.
4. Conclusion
Statement of authorship
Acknowledgements
References

\section{Introduction}

Clove is one of the environmental resources and export commodities that are quite reliable by the Indonesian government. Buleleng Regency is the largest clove producer in Bali where clove production data in this district in 2014 amounted to 5270.75 tons (an average of $745 \mathrm{~kg} /$ hectare) with an average area of 4 quarters of 7622.32 hectares and in 2015 its production 4907.39 tons (694 kg / hectare) with an average area of 7723.91 hectares of plantations [4], [5]. Provision of this production data using conventional methods, namely the calculation of production is carried out after harvest by collecting information on harvests from clove farmers. Quantitative assessment methods such as this require a long time, are not comprehensive, are less accurate, and provide results that are not real time, so they are not quick to make decisions about cloves. To overcome this, it takes the development of information technology or engineering the production information process with modern farming systems. An alternative method that can be used is the application of remote sensing satellite technology.

Vegetation index extracted from remote sensing data is a quantitative assessment of biomass in monitoring and managing natural/environmental resources. Several forms of vegetation index models are widely used in various studies related to global scale vegetation and can be effectively used for mapping land drought, desertification, deforestation to research on the productivity of a commodity [1], [8], [12]. Some of these studies use low spatial resolution data, such as the Moderate Resolution Imaging Spectroradiometer (MODIS) data which has several disadvantages, especially in narrow areas, some types of land cover are in one pixel, thus reducing the accuracy of the analysis [10]. Research on testing several algorithm models of vegetation index extracted from Landsat 8 image data results in a significant Ratio Vegetation Index (RVI) model which can be used in analyzing clove vegetation in Buleleng, Bali [13]. Landsat 8 image data has good spatial, temporal and spectral resolution, with many bands with the same pixel dimensions. This gives advantages in the development of vegetation index models [3].

This study aims to find a suitable vegetation index model and theory for the analysis of the distribution of clove vegetation in Buleleng regency, Bali through the development and optimization of RVI models in visible and infrared wavelength spectra of Landsat 8 imagery.

\section{Research Method}

The materials used were Landsat 8, 1 G level, May 5, 2014, for scene 1, Path 117, Row 66 and May 30, 2014, for scene 2, Path 116, Row 66. The study area is presented in Figure 1 and astronomically located in coordinates $8^{\circ} 03^{\prime} 40^{\prime \prime}-8^{\circ} 23^{\prime} 00^{\prime \prime}$ South Latitude and $114^{\circ} 25^{\prime} 55^{\prime \prime}-15^{\circ} 27^{\prime} 28^{\prime \prime}$ East Longitude.

The steps taken in this study were (1) coordinate measurements in the field (2) image data processing and analysis. At step (1), the coordinates of the sample of clove vegetation in the field are measured by selecting location points that are quite homogeneous using the Global Positioning System (GPS) Smartphone. This coordinate is used as an indicator of the position of clove vegetation at coordinates on Landsat 8 imagery. In step (2), it begins with making the study area image by mosaicing 2 scenes of Landsat 8 imagery, then overlaid 
with a digital map of the study area boundaries. Reflect correction on Top Of Atmosphere (TOA) using a formula from U.S. Geological Survey [11]. Geometric correction refers to 9 allied control points (Ground Control Point, GCPs) performed by the nearest neighbour method. To clarify visual interpretation and highlight aspects of vegetation, stretching using the Linear with Saturation method and building a composite image with a band combination, namely Red = band 6, Green = band 5 and Blue = band 4. Classification of clove and non-clove vegetation objects using the maximum method likelihood. The whole process of image data processing uses the IDRISI 17.0 The Selva Edition software.

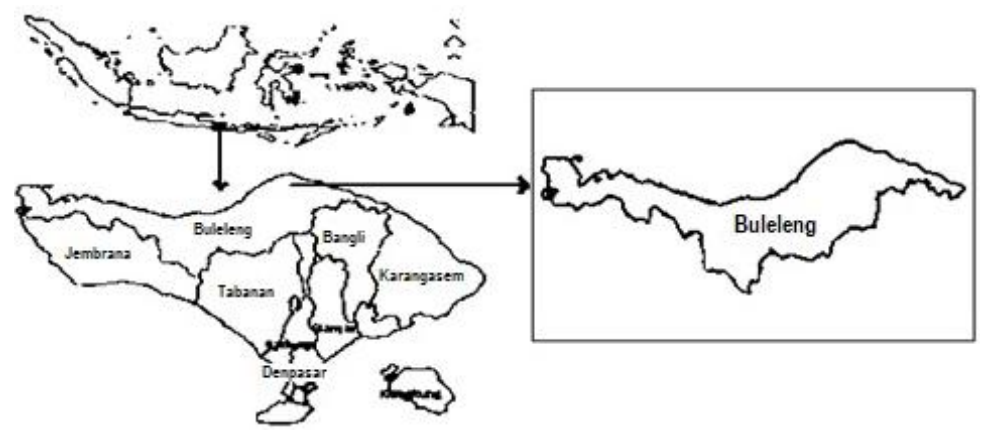

Figure 1. The regional research area of Buleleng Regency, Bali

Vegetation index development Ratio Vegetation Index (RVI) is oriented to the dominant spectral reflectance characteristics of the visible spectrum (band $3=\mathrm{B} 3$ ) and infrared spectrum (band $5=\mathrm{B} 5$, band $6=\mathrm{B} 6$ and band 7 = B7). Creating a linear relationship between RVI with B3, B5, B6, and B7 which are described in scattergram, produces 1 linear equation for each band and the number of equations produced is 4 . The vegetation index image that will be developed is formed from the RVI formula of development results which are multiple linear equations with 1 dependent variable and 4 independent variables labeled RVI $_{\text {new. }}$ Optimization strategy is carried out by dividing $\mathrm{RVI}_{\text {new }}$ with number factors that are variable with values from 1 to 4 according to the number of independent variables. More, processing and analyzing image data is presented in Figure 2.

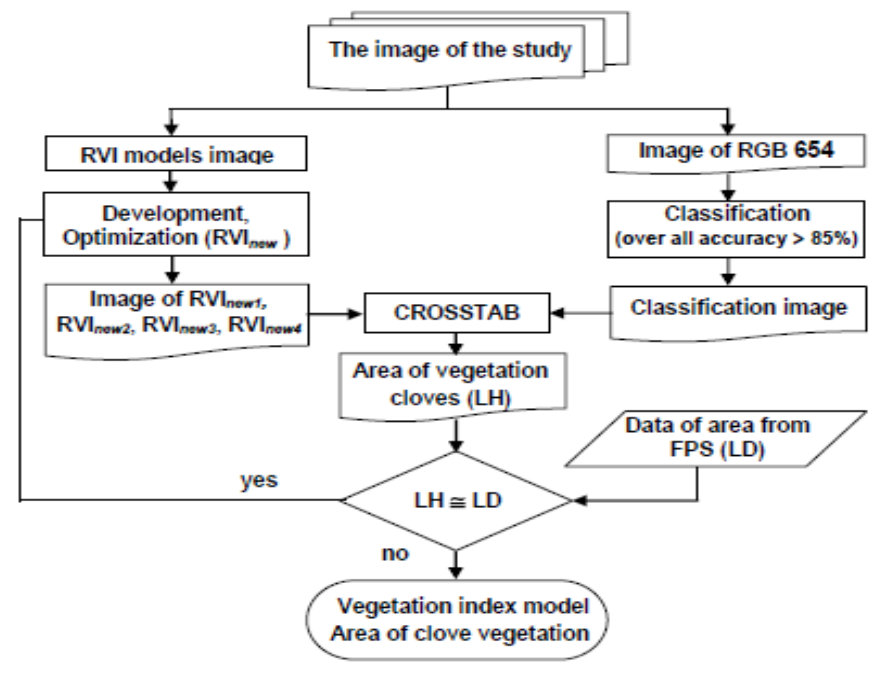

Figure 2. Research flow chart

Yuliara, I. M., Sutapa, G. N., \& Kasmawan, G. A. (2018). Development and optimization of the ratio vegetation index on the visible and infrared spectrum. International Journal of Physical Sciences and Engineering, 2(2), 101-110. https://doi.org/10.29332/ijpse.v2n2.172 


\section{Results and Analysis}

\subsection{Result}

The image of the study area was obtained by mosaicing 2 scene in Path 117, Row 66 and Path 116 , Row 66 from Landsat 8 image data for the Bali area which was then overlaid with a digital map of the study area boundaries. Geometric and Resample correction using 9 GCPs results in a total value of Root Mean Square (RMS) of 0.059. Contrast processing using Linear with Saturation method and formation of a composite image with RGB $=654$ band composition. The classification process to distinguish clove and non-clove vegetation objects using hard classification type and calculation of accuracy test with confusion matrix produce an overall accuracy of $89.16 \%$. The development of the RVI model is based on the sensitivity of the Landsat 8 sensor to the spectral reflectance on vegetation objects. Based on this, RVI's development strategy is associated with B3, B5, B6, and B7. The linear relationship described in scattergram between RVI with B3, B5, B6, and B7 produces 4 linear equations, namely:

$$
\begin{aligned}
& \mathrm{RVI}=-0.009770+0.005692 * \mathrm{~B} 3 \\
& \mathrm{RVI}=0.022705+0.001139 * \mathrm{~B} 5 \\
& \mathrm{RVI}=0.003099+0.002163 * \mathrm{~B} 6 \\
& \mathrm{RVI}=-0.007104+0.003828 * \mathrm{~B} 7
\end{aligned}
$$

The sum of the 4 equations forms a multiple linear equation with 1 dependent variable $\left(4 \mathrm{RVI}=\mathrm{RVI}_{\text {new }}\right)$ and 4 independent variables (B3, B5, B6 and B7), namely:

$$
\mathrm{RVI}_{\text {new }}=0.00893+0.00569 * \mathrm{~B} 3+0.00114 * \mathrm{~B} 5+0.00216 * \mathrm{~B} 6+0.00383 * \mathrm{~B} 7
$$

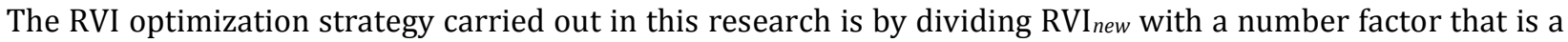
variable that is valued from 1 to 4 according to the number of independent variables used. The results of the RVI distribution were then labeled indexes, namely: $\mathrm{RVI}_{\text {new1 }}, \mathrm{RVI}_{\text {new2 }}, \mathrm{RVI}_{\text {new } 3}$ and $\mathrm{RVI}_{\text {new4 }}$. The vegetation index equations for the full optimization results are presented in the following equation:

$$
\begin{aligned}
& \mathrm{RVI}_{\text {new } 1}=\mathrm{RVI}_{\text {new }} / 1=0.00893+0.00569 * \mathrm{~B} 3+0.00114 * \mathrm{~B} 5+0.00216 * \mathrm{~B} 6+0.00383 * \mathrm{~B} 7 \\
& \mathrm{RVI}_{\text {new } 2}=\mathrm{RVI}_{\text {new }} / 2=0.00447+0.00285^{*} \mathrm{~B} 3+0.00057 * \mathrm{~B} 5+0.00108 * \mathrm{~B} 6+0.00191 * \mathrm{~B} 7 \\
& \mathrm{RVI}_{\text {new } 3}=\mathrm{RVI}_{\text {new }} / 3=0.00298+0.00190 * \mathrm{~B} 3+0.00038 * \mathrm{~B} 5+0.00072 * \mathrm{~B} 6+0.00128 * \mathrm{~B} 7 \\
& \mathrm{RVI}_{\text {new } 4}=\mathrm{RVI}_{\text {new }} / 4=0.00223+0.00142 * \mathrm{~B} 3+0.00028 * \mathrm{~B} 5+0.00054 * \mathrm{~B} 6+0.00096 * \mathrm{~B} 7
\end{aligned}
$$

One of the results of the image from the application of the RVI optimization is presented in Figure 3.

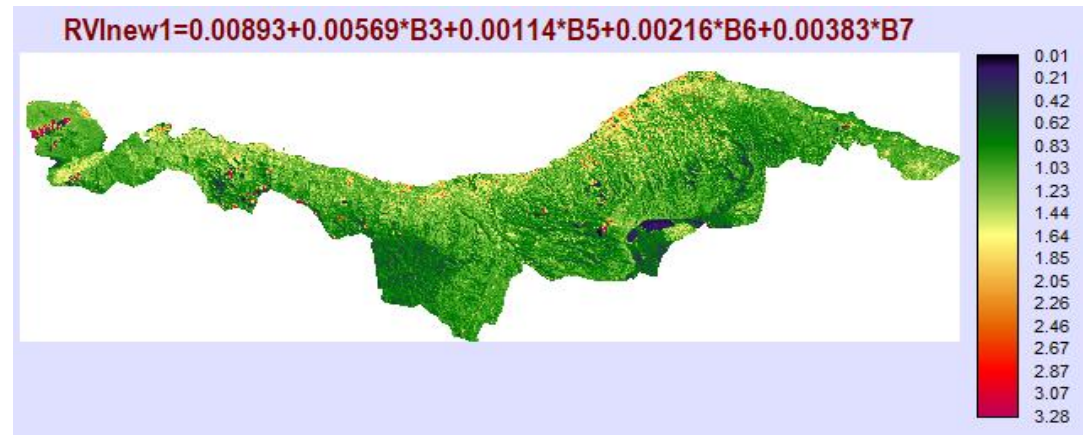

Figure 3. Vegetation index distribution image based on $\mathrm{RVI}_{\text {new } 1}$

Geographical coordinate measurements using smartphone GPS applications and vegetation index values indicated as clove vegetation for each vegetation index model from the optimization results on 10 observation points (OP) are presented in Table 1, while the histogram graph is presented in Figure 4. 
Table 1

Value of RVI optimization at each OP

\begin{tabular}{ccccccccc}
\hline \multirow{2}{*}{ OP } & \multicolumn{2}{c}{ Geographical Coordinates } & \multicolumn{2}{c}{ Image Coordinates } & \multicolumn{4}{c}{ Value } \\
\cline { 2 - 8 } & Latitude & Longitude & colomn & row & $\mathrm{RVI}_{\text {new } 1}$ & $\mathrm{RVI}_{\text {new } 2}$ & $\mathrm{RVI}_{\text {new } 3}$ & $\mathrm{RVI}_{\text {new } 4}$ \\
\hline 1 & 295080 & 9092700 & 2259 & 901 & 0.66315 & 0.33151 & 0.22292 & 0.16509 \\
2 & 295140 & 9092876 & 2608 & 557 & 0.60493 & 0.30240 & 0.20338 & 0.15065 \\
3 & 294840 & 9093986 & 2615 & 588 & 0.70138 & 0.35057 & 0.23594 & 0.17469 \\
4 & 295050 & 9093055 & 2616 & 600 & 0.67475 & 0.33725 & 0.22694 & 0.16807 \\
5 & 284370 & 9083666 & 2618 & 594 & 0.77012 & 0.38487 & 0.25904 & 0.19191 \\
6 & 295260 & 9092336 & 2622 & 612 & 0.84293 & 0.42130 & 0.28346 & 0.20993 \\
7 & 307110 & 9098875 & 2988 & 362 & 0.64259 & 0.32133 & 0.21600 & 0.15997 \\
8 & 306240 & 9099837 & 2994 & 374 & 0.72665 & 0.36328 & 0.24418 & 0.18093 \\
9 & 306420 & 9099475 & 3017 & 394 & 0.56782 & 0.28383 & 0.19092 & 0.14143 \\
10 & 307590 & 9097255 & 3033 & 448 & 0.87471 & 0.43734 & 0.29386 & 0.21773 \\
\hline \multicolumn{3}{c}{ Average } & & & 0.70690 & 0.35337 & 0.23766 & 0.17604 \\
\hline
\end{tabular}

The pixel processing image indicated as clove vegetation from one of the optimization vegetation indices, namely $\mathrm{RVI}_{\text {new } 1}$ is presented in Figure 5.

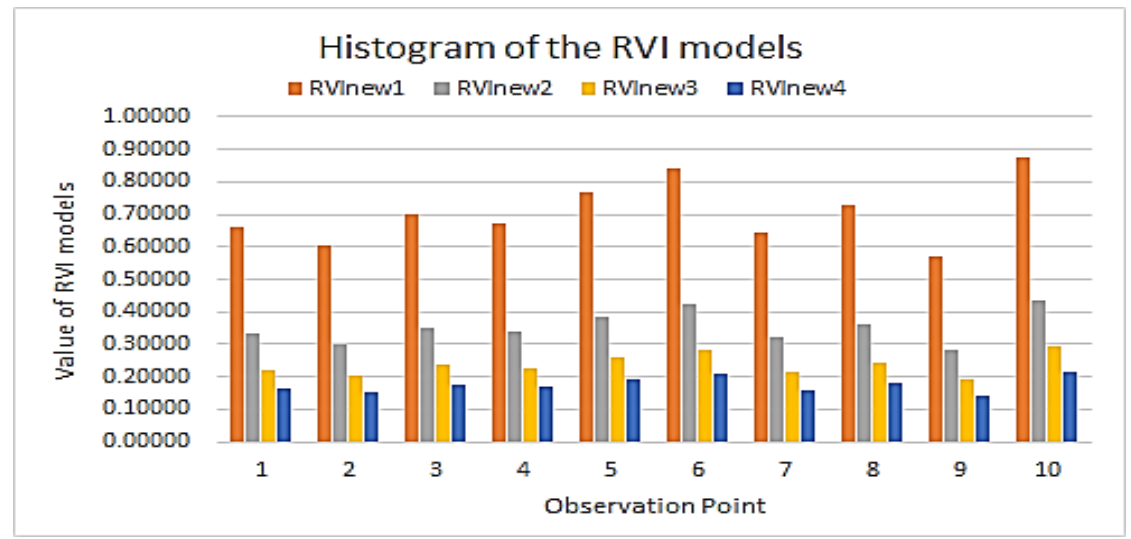

Figure 4. Histogram of the RVI model optimization

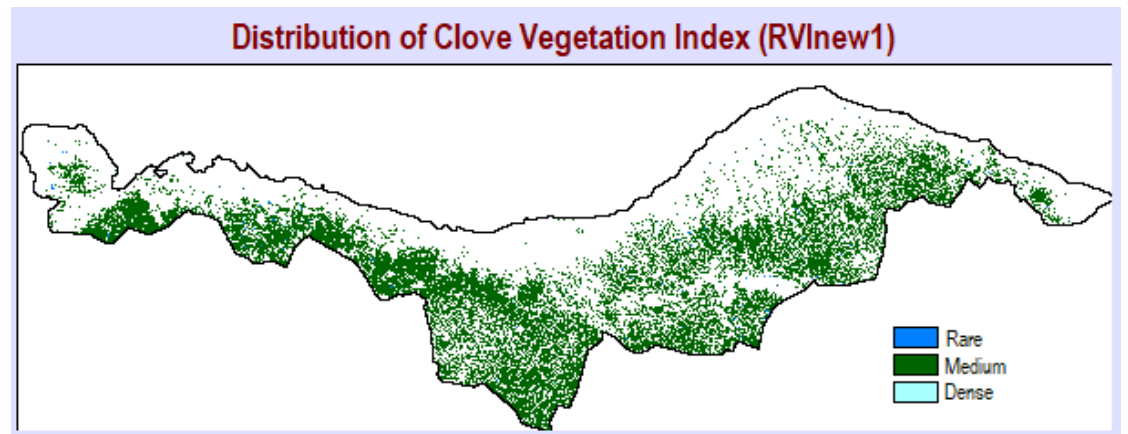

Figure 5. Distribution of clove vegetation index based on RVInew1

Identification of clove vegetation distribution based on optimization vegetation index was obtained from the Cross Tabulation process between RVI optimization imagery and clove and non-clove classification images using the CROSSTAB module available on IDRISI 17.0 The Selva Edition. To determine the categories or

Yuliara, I. M., Sutapa, G. N., \& Kasmawan, G. A. (2018). Development and optimization of the ratio vegetation index on the visible and infrared spectrum. International Journal of Physical Sciences and Engineering, 2(2), 101-110. https://doi.org/10.29332/ijpse.v2n2.172 
classes of the density of clove vegetation, namely, rare, medium and dense classes carried out reclassification. The results of statistical data processing obtained by the area of clove vegetation and density class area from the optimization vegetation index model as presented in Table 2, while the image of clove vegetation distribution is presented in Figure 6.

Table 2

Area of clove vegetation and density class of RVI optimization

\begin{tabular}{|c|c|c|c|c|c|}
\hline \multirow{2}{*}{ No } & \multirow{2}{*}{ Models } & \multirow{2}{*}{ Area (ha) } & \multicolumn{3}{|c|}{ Area of Density Class (ha) } \\
\hline & & & Rare & Medium & Dense \\
\hline 1 & $\mathrm{RVI}_{\text {new1 }}$ & 7669.08 & 7444.89 & 20.52 & 203.67 \\
\hline 2 & $\mathrm{RVI}_{\text {new2 }}$ & 7668.81 & 7448.49 & 20.25 & 200.07 \\
\hline 3 & $\mathrm{RVI}_{\text {new3 }}$ & 7670.70 & 7427.79 & 21.69 & 221.22 \\
\hline 4 & $\mathrm{RVI}_{\text {new4 }}$ & 7667.82 & 7441.74 & 20.61 & 205.47 \\
\hline \multicolumn{2}{|c|}{ Average } & 7669.10 & 7440.73 & 20.77 & 207.61 \\
\hline
\end{tabular}

The comparison of the total area of clove vegetation based on models of the RVI vegetation index with data on the area of clove vegetation in 2014 from the Forestry and Plantation Service (FPS) of Buleleng regency is presented in Table 3.

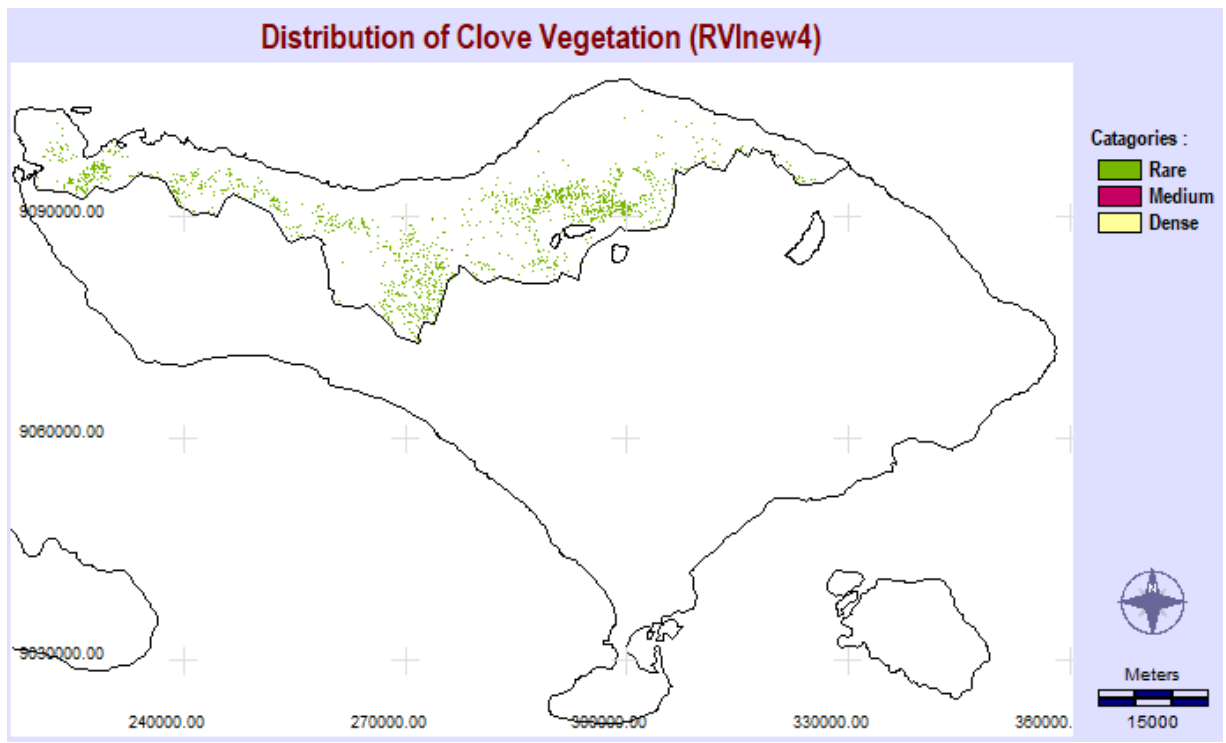

Figure 6. Distribution of clove vegetation based on RVInew4

Table 3

Comparison of the area value of the RVI optimization model with the FPS of Buleleng Regency

\begin{tabular}{|c|c|c|c|c|}
\hline \multirow[t]{2}{*}{ No } & \multicolumn{2}{|c|}{ RVI Model and Area } & \multirow{2}{*}{$\begin{array}{l}\text { Average Area of FPS, } \\
\text { Buleleng Regency (ha) }\end{array}$} & \multirow{2}{*}{$\begin{array}{c}\text { Percentage of } \\
\text { Comparison ( \% ) }\end{array}$} \\
\hline & Models & Area (ha) & & \\
\hline 1 & $\mathrm{RVI}_{\text {new1 }}$ & 7669.08 & 7622.32 & 99.390 \\
\hline 2 & $\mathrm{RVI}_{\text {new2 }}$ & 7668.81 & 7622.32 & 99.393 \\
\hline 3 & $\mathrm{RVI}_{\text {new3 }}$ & 7670.70 & 7622.32 & 99.369 \\
\hline 4 & $\mathrm{RVI}_{\text {new } 4}$ & 7667.82 & 7622.32 & 99.401 \\
\hline
\end{tabular}

\subsection{Analysis}

Image processing stages in this study generally have met the Standard Operational Procedure [6], [7]. Both in quality and quantity give good results, such as geometric and resample correction results, the total value of 
Root Mean Square (RMS) is 0.059 . This result is very good in providing certainty about the position of objects in the image and making the image have a reference (georegistration) at the UTM zone 50N coordinates [7]. Stretching processing uses the Linear with Saturation method and the formation of composite images with RGB $=654$ band composition. Producing better visualization compared to single band images and different objects visually appear clearer [6], [7].

The basis of RVI development and optimization is oriented to several research results which show that the reflectance percentage of vegetation is quite large in the visible spectrum, especially in B3 and in the infrared spectrum, namely B5, B6 and B7 [9], [13]. The use of these 4 bands in developing vegetation indices, provides convenience in shaping vegetation index models [3]. From the results of the development of the vegetation index model (RVInew) in this study, the regression variable constants are quite small, this shows very carefully every variable constant generated by the scattergram of each band.

Optimization vegetation index models $\left(\mathrm{RVI}_{\text {new1 }}, \mathrm{RVI}_{\text {new2 }}, \mathrm{RVI}_{\text {new3 }}\right.$, and $\left.\mathrm{RVI}_{\text {new4 }}\right)$ provide indicators that, each image of the optimization vegetation index model will indicate the difference in the index value of clove vegetation in the image. The existence of this difference affects the results of the identification of the distribution of clove vegetation objects carried out by the CROSSTAB process, thus giving the results of different area calculations. This is highly expected because in accordance with the optimization strategy, want to get the area of vegetation produced by the optimization vegetation index approaching the extensive data from the FPS of Buleleng regency.

From Table 1, it can be seen that the highest average value of $\mathrm{RVI}_{\text {new } 1}=0.70690$ while the smallest $\mathrm{RVI}_{\text {new4 }}$ $=0.15997$. This is caused by the divider number for $\mathrm{RVI}_{\text {new } 1}<\mathrm{RVI}_{\text {new4 }}$. The observation point 9 provides the smallest value of RVI optimization and this means the least green level distribution compared to other observation points [2], [3]. This situation is also very clearly seen in the histogram view in Figure 4. However, more important in addressing this situation is the result of the optimization vegetation index value al ready in the index value interval for vegetation in general, which is between 0 to 1 [2], [9]. The greater the value of the vegetation index in a vegetation location produced by 1 vegetation index model, shows the healthier or fertile vegetation at that location [7]. In other words, it can also mean that the greater the value of the vegetation index, the more closely the vegetation cover that covers the land. In Figure 5 it can be interpreted that, the category of value of RVInew1 optimization vegetation index is dominated by medium density vegetation index.

Distribution of clove vegetation is presented in Figure 6 and the area produced by RVI new models gives different values, as presented in Table 2. The largest value is given by RVI new3 model, which is 7670.70 ha and the smallest is by RVInew4 model, which is 7667.82 ha. When compared with the broad value of the 2014 FPS Buleleng regency, which is equal to 7622.32 ha, then according to the data in Table 2, the RVI new4 $_{4}$ model area is the least difference in value, which is $45.50 \mathrm{ha}$, while the broad value difference the largest given by the area of the $\mathrm{RVI}_{\text {new }}$ model, which is 48.38 ha. The average area of the four optimization vegetation index models is $7669.10 \mathrm{ha}$. The area for the category of clove vegetation density produced by the 4 models of optimization vegetation index is an average of 7440.73 ha for rare classes, and 20.77 ha for medium class and 207.61 ha for heavy class. Seeing the broad results of the three categories of this class, the class is rarely a dominating class. The total pixels identified as clove vegetation are 86975 pixels. Table 3 shows the broad comparison for each model of the vegetation index optimization to the extent of data from the Forestry and Plantation Service, Buleleng regency, Bali. The biggest percentage is given by $\mathrm{RVI}_{\text {new }}$ model, which is $99.401 \%$ and the smallest by $\mathrm{RVI}_{\text {new3 }}$ model is $99.396 \%$.

\section{Conclusion}

There are 4 forms of RVI vegetation index models from the development and optimization of the visible and infrared spectra. The form that gives results close to the extent of the Forestry and Plantation Service, Buleleng regency, Bali is $\mathrm{RVI}_{\text {new }}=0.0022+0.00142 * \mathrm{~B} 3+0.00028 * \mathrm{~B} 5+0.00054 * \mathrm{~B} 6+0.00096 * \mathrm{~B} 7$. The area produced by this model is 7667.82 ha. This result is the closest value or about $99.40 \%$ of the data area of the Forestry and Plantation Service, Buleleng regency, Bali, which is 7622.32 ha. The dominant distribution of clove vegetation is in the rare category with an area of 7441.74 ha.

Yuliara, I. M., Sutapa, G. N., \& Kasmawan, G. A. (2018). Development and optimization of the ratio vegetation index on the visible and infrared spectrum. International Journal of Physical Sciences and Engineering, 2(2), 101-110. https://doi.org/10.29332/ijpse.v2n2.172 
Conflict of interest statement and funding sources

The authors declared that they have no competing interest. The study was financed by Udayana University.

Statement of authorship

The authors have a responsibility for the conception and design of the study. The authors have approved the final article.

\section{Acknowledgments}

The authors would like to thank Udayana University for funding this research through the Leading Research Scheme from the Study Program, the year 2018. 


\section{References}

1. Adams, J. B., \& Gillespie, A. R. (2006). Remote sensing of landscapes with spectral images: A physical modeling approach. Cambridge University Press.

View in (Google Scholar)

2. Barbosa, H. A., Huete, A. R., \& Baethgen, W. E. (2006). A 20-year study of NDVI variability over the Northeast Region of Brazil. Journal of arid environments, 67(2), 288-307.

View in (Google Scholar)

3. Small, C. (2004). The Landsat ETM+ spectral mixing space. Remote sensing of Environment, 93(1-2), 1-17.

View in (Google Scholar)

4. Forestry and Plantation Service of Buleleng Regency. (2014). Quarterly Area Report and Production of Buleleng Regency Plantation Commodities in 2014.

View in (Google Scholar)

5. Forestry and Plantation Service of Buleleng Regency. (2015). Quarterly Area Report and Production of Buleleng Regency Plantation Commodities in 2015.

View in (Google Scholar)

6. Lillesand, T., Kiefer, R. W., \& Chipman, J. (2014). Remote sensing and image interpretation. John Wiley \& Sons.

View in (Google Scholar)

7. Mather, P. M., \& Koch, M. (2011). Computer processing of remotely-sensed images: an introduction. John Wiley \& Sons.

View in (Google Scholar)

8. Shao, Y., Fan, X., Liu, H., Xiao, J., Ross, S., Brisco, B., ... \& Staples, G. (2001). Rice monitoring and production estimation using multitemporal RADARSAT. Remote sensing of Environment, 76(3), 310-325.

View in (Google Scholar)

9. Song, C., Gray, J. M., \& Gao, F. (2011). Remote sensing of vegetation with landsat imagery. Advances in Environmental Remote Sensing: Sensors, Algorithms, and Applications, 3-29.

View in (Google Scholar)

10. Strahler, A. H., Boschetti, L., Foody, G. M., Friedl, M. A., Hansen, M. C., Herold, M., ... \& Woodcock, C. E. (2006). Global land cover validation: Recommendations for evaluation and accuracy assessment of global land cover maps. European Communities, Luxembourg, 51(4).

View in (Google Scholar)

11.USGS. (2017). Using the USGS Landsat 8 Product, U.S. Geological Survey. http://landsat.usgs.gov/Landsat8_Using_Product.php Retrieved on June 1, 2017.

View in (Article)

12.Xie, Y., Sha, Z., \& Yu, M. (2008). Remote sensing imagery in vegetation mapping: a review. Journal of plant ecology, 1(1), 9-23.

View in (Google Scholar)

13.Yuliara, A. Kasmawan. (2017). The Reflectance Spectral Characteristic of Cloves Vegetation Using Landsat 8 in Buleleng Bali, Journal of Food Security and Agriculture (Vol. 1). 15 - 17 . IRCS. Udayana University Press.

View in (Article)

Yuliara, I. M., Sutapa, G. N., \& Kasmawan, G. A. (2018). Development and optimization of the ratio vegetation index on the visible and infrared spectrum. International Journal of Physical Sciences and Engineering,

2(2), 101-110. https://doi.org/10.29332/ijpse.v2n2.172 


\section{Biography of Authors}

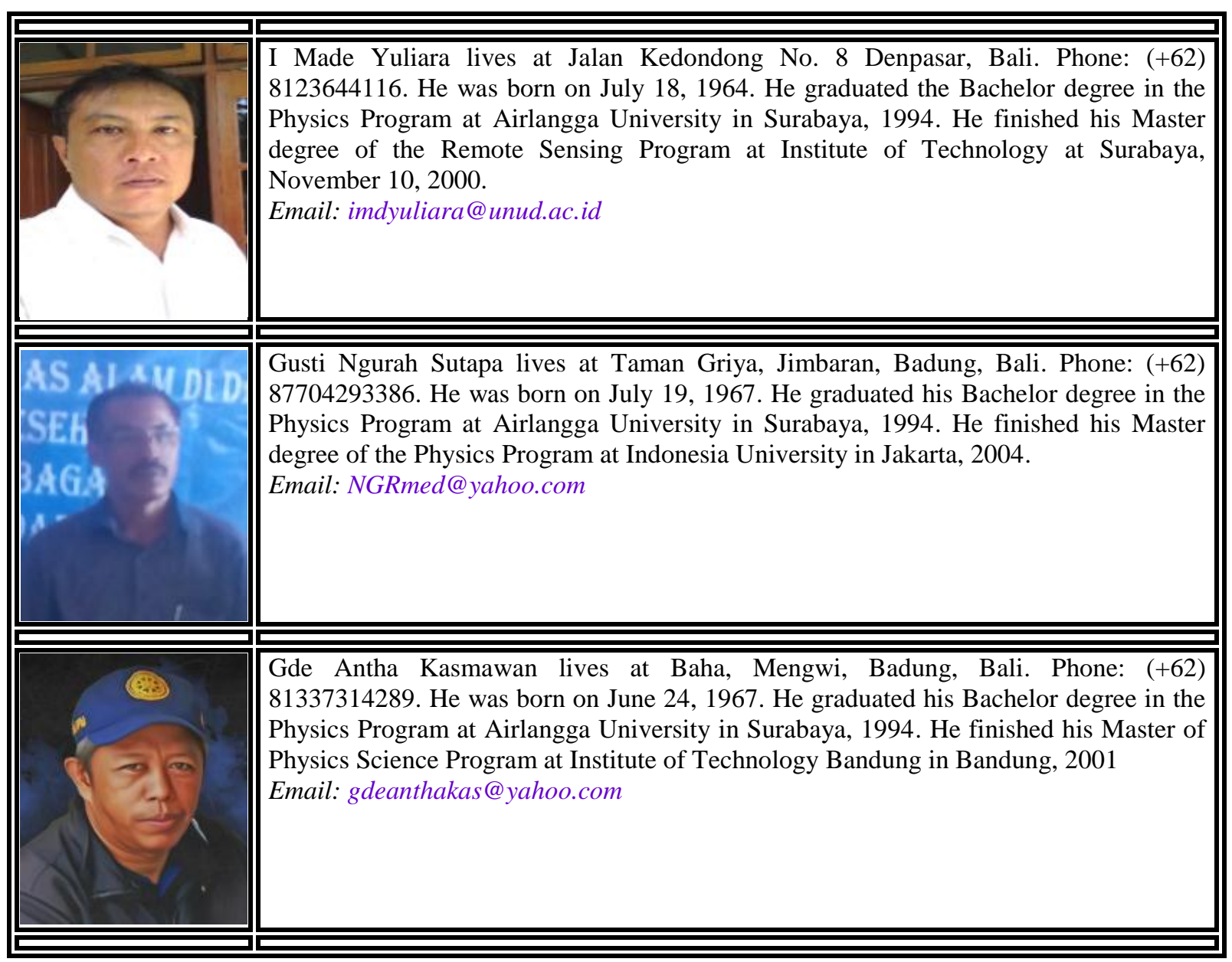

